\title{
Clinical observation of the efficacy of Bevacizumab combined with argon green laser in treating fundus macular edema
}

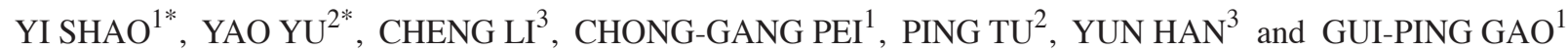 \\ ${ }^{1}$ Department of Ophthalmology, The First Affiliated Hospital of Nanchang University, Jiangxi Province Clinical \\ Ophthalmology Institute, Nanchang, Jiangxi 330006; ${ }^{2}$ Department of Endocrinology and Metabolism, The Third Hospital \\ of Nanchang, Nanchang Key Laboratory of Diabetes, Nanchang, Jiangxi 330009; ${ }^{3}$ Fujian Province Key Laboratory \\ of Ophthalmology and Vision Research, Eye Institute of Xiamen University, Xiamen, Fujian 361102, P.R. China
}

Received June 27, 2016; Accepted January 26, 2017

DOI: $10.3892 / \mathrm{etm} .2017 .4145$

\begin{abstract}
We studied the clinical efficacy of Bevacizumab combined with argon green laser in treating fundus macular edema. From May 2009 to April 2013, 78 patients seeking treatment for macular edema in the First Affiliated Hospital of Nanchang University were enrolled in this study. Patients were randomly divided into two groups: i) The experimental group $(n=39)$ and the control group $(n=39)$. Patients in the experimental group were treated with Bevacizumab $\left(\right.$ Avastin $\left.^{\circledR}\right)$ combined with argon green laser, and those in the control group were treated exclusively with argon green laser. Therapeutic effects were compared, and postoperative adverse reactions caused by both treatment methods were compared. Our results showed that, after treatment, the macular foveal thickness was reduced noticeably in both groups, while the therapeutic effect of combined treatment was more prominent. Patients in the experimental group gained the best-corrected visual acuity after one month of treatment, while patients in the control group achieved that after three months of treatment. We concluded that the use of Avastin ${ }^{\circledR}$ combined with argon green laser was safe and effective. Visual acuity was improved obviously with minimum adverse reactions.
\end{abstract}

Correspondence to: Dr Gui-Ping Gao, Department of Ophthalmology, The First Affiliated Hospital of Nanchang University, Jiangxi Province Clinical Ophthalmology Institute, 17 Yongwaizheng Street, Nanchang, Jiangxi 330006, P.R. China E-mail: guipingao@163.com

Dr Yun Han, Fujian Province Key Laboratory of Ophthalmology and Vision Research, Eye Institute of Xiamen University, South Xiang'an Road, Xiamen, Fujian 361102, P.R. China

E-mail: yunhann430@163.com

*Contributed equally

Key words: fundus macular edema, Avastin, argon green laser

\section{Introduction}

Macula flava is the most sensitive spot on the retina. The macular edema is an inflammatory reaction of the macula falva, which is caused by fluid infiltration and can lead to a severe reduction in the visual acuity (1). The macular edema is the ocular manifestation of conditions such as central retinal vein occlusion, diabetic retinopathy and uveitis (2). Currently, the treatment of the macular edema is focused on pathogeny correction and symptomatic treatment. IgG1 antibody can attach to vascular endothelial growth factor (VEGF) and block its biological activity. This way it can inhibit blood vessel growth, which has a prominent effect on treating macula edema caused by diabetes (3). Bevacizumab (Avastin ${ }^{\circledR}$ ) is a recombinant humanized monoclonal antibody that plays a significant role in the targeted therapy in rectal cancer (4).

With the development of the fundus laser photocoagulation treatment, more and more fundus diseases are being cured fundamentally. Among these therapies, argon green laser can make accretion of the retina scar through sealing the leaky microvascular artery, thus promotes the regeneration of the retina pigment epithelium and rebuilds the blood-retina barrier, which accelerates the absorption of the edema (5). We employed Avastin ${ }^{\circledast}$ combined with argon green laser in treating macular edema and achieved satisfactory results.

\section{Materials and methods}

Group criteria. Inclusion criteria: Patients diagnosed with fundus macular edema by slit lamp, 90D preset lens, three-mirror contact lens, indirect ophthalmoscope, intraocular tension, and OCT examination.

Exclusion criteria: i) Patients without macular edema; ii) patients with cataract; iii) patients allergic to Avastin ${ }^{\circledR}$; iv) patients who refused to sign informed consent papers; v) patients who were treated with surgery or medicine; and vi) patients with mental or nervous system diseases.

Clinical information. From May 2009 to April 2013, 78 patients seeking treatment for macular edema in the First Affiliated Hospital of Nanchang University were enrolled in 
Table I. Comparisons on basic information of patients with macula rhegmatogenous retinal detachment.

\begin{tabular}{lccccc}
\hline Groups & Case & Age (years) & Course of disease (years) & logMAR-BCVA & Visual acuity $\left(^{\circ}\right.$ ) \\
\hline Experimental & 39 & $48.8 \pm 2.3$ & $1.6 \pm 0.75$ & $1.42 \pm 0.67$ & $0.01 \pm 0.011$ \\
Control & 39 & $43.6 \pm 1.1$ & $1.8 \pm 0.83$ & $1.51 \pm 0.87$ & $0.01 \pm 0.012$ \\
F-value & - & 0.37 & 0.78 & 0.28 & 0.07 \\
P-value & - & $>0.05$ & $>0.05$ & $>0.05$ & $>0.05$ \\
\hline
\end{tabular}

Table II. Central foveal thickness of the macular lutea before and after treatment.

\begin{tabular}{|c|c|c|c|c|c|c|}
\hline Groups & Case & $\begin{array}{c}\text { Before } \\
\text { surgery }(\mu \mathrm{m})\end{array}$ & $\begin{array}{l}1 \text { day after } \\
\text { surgery }\end{array}$ & $\begin{array}{c}1 \text { month after } \\
\text { surgery }\end{array}$ & $\begin{array}{l}3 \text { months after } \\
\text { surgery }\end{array}$ & $\begin{array}{c}6 \text { months after } \\
\text { surgery }\end{array}$ \\
\hline Experimental & 39 & $387.3 \pm 12.2$ & $382.3 \pm 9.7$ & $335.4 \pm 28.7^{\mathrm{a}}$ & $267.8 \pm 18.4^{\mathrm{b}}$ & $234.4 \pm 9.8$ \\
\hline Control & 39 & $389.2 \pm 10.7$ & $386.5 \pm 7.2$ & $354.8 \pm 12.5^{\mathrm{a}}$ & $292.4 \pm 13.6^{b}$ & $278.5 \pm 10.4$ \\
\hline T-value & - & 0.43 & 0.46 & 12.7 & 28.6 & 31.4 \\
\hline P-value & - & 0.17 & 0.57 & 0.011 & 0.014 & 0.015 \\
\hline
\end{tabular}

${ }^{\mathrm{a} C}$ Compared to the value before surgery, the differences were statistically significant, $\mathrm{P}<0.05$. ${ }^{\mathrm{b}} \mathrm{Compared}$ to the value 1 month after surgery, the differences were statistically significant, $\mathrm{P}<0.05$.

this study. There were 28 males and 50 females with average age of $46.6 \pm 7.5$ years. The courses of the disease ranged from 6 months to 3.8 years (average, $1.52 \pm 0.73$ years), and the medium course was 1.3 years. Patients were divided into two groups on random control principle (Table I). Information such as age, disease course, visual acuity in two groups had no statistical differences $(\mathrm{P}>0.05)$. This study was approved by the Ethics Committee in the First Affiliated Hospital of Nanchang University, and the patients or their families signed the written informed consent papers.

\section{Examination methods}

Intracavitary injection of Avastin ${ }^{\circledR}$ into vitreous chamber (6). Before surgery, we applied tropicamide (Yangze Pharma, Taizhou, China) to dilate the pupil. Patients were draped and sterilized, conjunctival sac was flushed, and surface anesthesia with Alcaine (Yangze Pharma) was conducted. The anterior chamber was punctured under the conducted. The anterior chamber was punctured under the slit lamp microscope (Mule Co., Hangzhou, China), and $0.1 \mathrm{ml}$ of anterior aqueous fluid was collected. We vertically punctured the bulbar conjunctiva and sclera from the spot $3.5 \mathrm{~mm}$ behind the corneal limbus under the temple. We reached the posterior segment of the vitreous chamber and slowly injected the Avastin ${ }^{\circledR}$ solution into the chamber at the rate of $0.1 \mathrm{ml} / \mathrm{min}$ (total volume, $0.05 \mathrm{ml}$ ). Needle hole was gently pressed the with wet cotton bud after injection for 1 to $2 \mathrm{~min}$, and intraocular tension was then examined. If the intraocular tension was not high, we applied tobramycin eye ointment.

Argon green laser therapy (7). Tropicamide was applied to dilate the pupil and local leaky spot was sealed using photocoagulation (distance from the central fovea was $500 \mu \mathrm{m}-1 \mathrm{~mm}$, diameter of the light spot was 50-100 $\mu \mathrm{m}$, exposure time was set at $0.1 \mathrm{sec}$, the energy was $75-100 \mathrm{~mW}$, and reaction was class I of spot size effect classification). Visual acuity was re-examined at 1, 3, 6 and 12 months after surgery and the fundus fluorescein angiography examined 3 months after surgery.

$90 D$ preset lens examination (8). During the examination, patients kept the same position and posture with the slit lamp. Tropicamide was applied and the preset lens was placed, while the light angle and the microscope was adjusted. The focus point was regulated until the vitreous body and the position of fundus lesion could be seen clearly.

Intraocular tension examination (9). Intraocular examination with non-contact ophthalmotonometer (NT-2000; Siou Co., Shanghai, China) was conducted. Patient's posture was adjusted before the examination, and submaxilla was placed on the bracket of the examination machine properly. Both eyes look forward at the same time. Eyes were opened to a certain degree and were made to stare at the indication point of the machine. The non-contact ophthalmotonometer was used for examination with airflow. Eyes were enjoined to avoid blinking while the examiner regulated the controlling lever to focus. When regulation was completed, intraocular tension was examined, and the average value was recorded after 3 successive examinations.

Statistical analysis. All quantitative data were expressed as mean \pm standard deviation. Comparison between groups was done using Student's t-test. Percentage (\%) was used to express the enumeration data and Chi-square test was used for data analysis. A P-value of $<0.05$ was considered to indicate a statistically significant difference.

\section{Results}

Central foveal thickness of the macular lutea before and after treatment. We compared the central foveal thickness of the macular lutea in both groups before and after treatment. 
Table III. Comparison of the logMAR-BCVA in both groups.

\begin{tabular}{lcccccc}
\hline Groups & Case & $\begin{array}{c}\text { Before } \\
\text { surgery }\end{array}$ & $\begin{array}{c}1 \text { day after } \\
\text { surgery }\end{array}$ & $\begin{array}{c}1 \text { month after } \\
\text { surgery }\end{array}$ & $\begin{array}{c}3 \text { months after } \\
\text { surgery }\end{array}$ & $\begin{array}{c}6 \text { months after } \\
\text { surgery }\end{array}$ \\
\hline Experimental & 39 & $1.25 \pm 0.67$ & $1.23 \pm 0.71$ & $1.48 \pm 0.82^{\mathrm{a}}$ & $1.49 \pm 0.95$ & $1.49 \pm 0.72$ \\
Control & 39 & $1.22 \pm 0.87$ & $1.22 \pm 0.69$ & $1.29 \pm 0.55$ & $1.22 \pm 0.28$ & $1.31 \pm 0.21^{\mathrm{b}}$ \\
T-value & - & 0.68 & 0.38 & 12.64 & 0.37 \\
P-value & - & $>0.05$ & 0.77 & 0.018 & 0.021 & 0.26 \\
\hline
\end{tabular}

${ }^{\mathrm{a} C o m p a r e d ~ t o ~ t h e ~ v a l u e ~ b e f o r e ~ s u r g e r y, ~ t h e ~ d i f f e r e n c e s ~ w e r e ~ s t a t i s t i c a l l y ~ s i g n i f i c a n t, ~} \mathrm{P}<0.05$. ${ }^{\mathrm{b}} \mathrm{Compared}$ to the value before surgery, the differences were statistically significant, $\mathrm{P}<0.05$.

Table IV. Time before reaching the best-corrected visual acuity (day).

\begin{tabular}{lcc}
\hline Groups & Case & $\begin{array}{c}\text { Time taken to reach the } \\
\text { best-corrected visual acuity }\end{array}$ \\
\hline $\begin{array}{l}\text { Experimental } \\
\text { Control }\end{array}$ & 39 & $29.7 \pm 7.8$ \\
T-value & 39 & $172.6 \pm 12.4$ \\
P-value & - & 49.3 \\
\hline
\end{tabular}

Table V. Comparison of the therapeutic effects.

\begin{tabular}{|c|c|c|c|c|}
\hline Groups & Case & Effective & Ineffective & $\begin{array}{c}\text { Rate of } \\
\text { effectiveness }\end{array}$ \\
\hline Experimental & 39 & 37 & 2 & 0.95 \\
\hline Control & 39 & 32 & 7 & 0.82 \\
\hline P-value & - & \multicolumn{2}{|c|}{0.48} & 0.27 \\
\hline
\end{tabular}

Results indicated that the macular central foveal thickness in both groups reduced significantly after treatment, while the therapeutic effect of the group with combined treatment was more prominent. Differences were statistically significant $(\mathrm{P}<0.05)$ (Table II).

Best-corrected visual acuity. Patients in the combined treatment group achieved the best-corrected visual acuity one month after treatment, while patients in the green laser group achieved the best-corrected visual acuity three months after treatment. Differences were statistically significant $(\mathrm{P}<0.05)$. However, after 6 months, the differences in visual acuity in both groups were not statistically significant $(\mathrm{P}>0.05)$ (Table III and Fig. 1).

The average time to reach the best-corrected visual acuity in the experimental group was $29.7 \pm 7.8$ days while this time in the control group was $172.6 \pm 12.4$ days. Differences were statistically significant $(\mathrm{P}<0.05)$ (Table IV and Fig. 2).

Therapeutic effect. Therapeutic effects of two methods were compared one year after treatment, and no statistically significant difference was detected $(\mathrm{P}>0.05)$ (Table V).

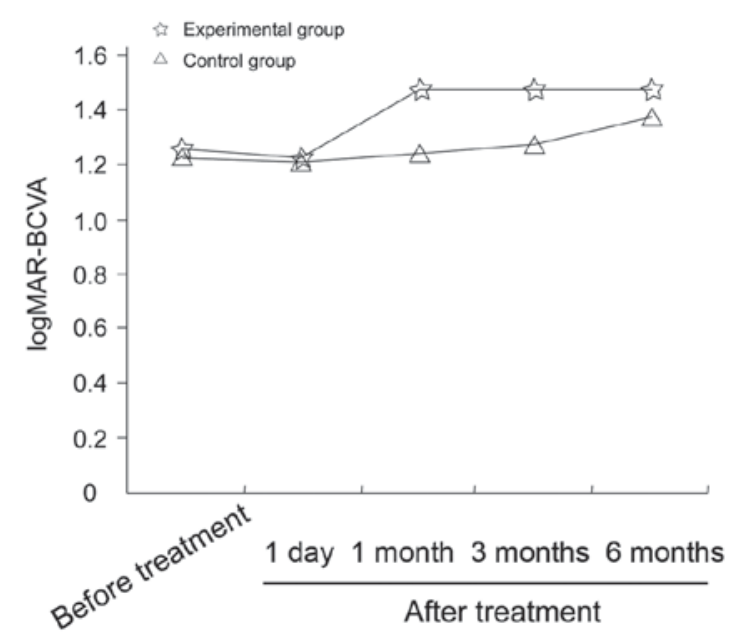

Figure 1. The $\log$ MAR-BCVA after treatment increased in both groups, while the increase of the visual acuity in the experimental group during the period of 1 day to 1 month after surgery was prominently higher than that of the control group. The differences were statistically significant $(\mathrm{P}<0.05)$.

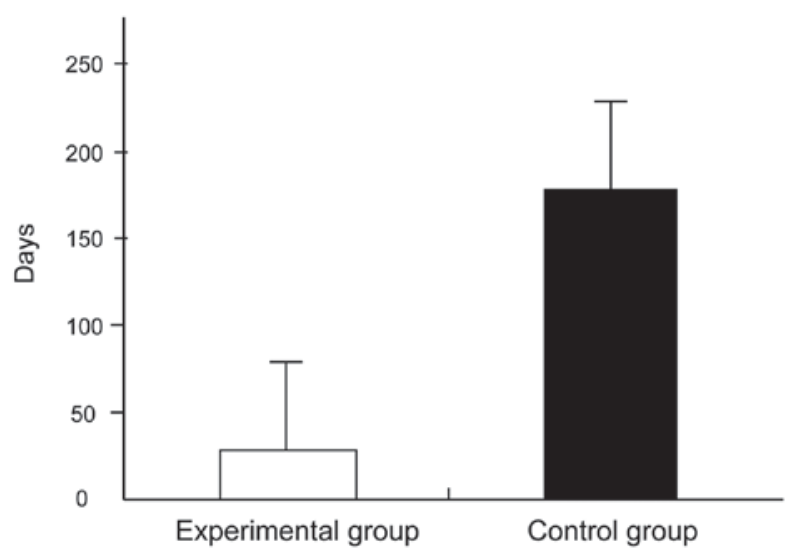

Figure 2. Comparison was made on the average time to reach the best-corrected visual acuity between two groups. The results indicated that the time to reach the best-corrected visual acuity for the patients in the experimental group was $29.7 \pm 7.8$ days, while that in the control group was $172.6 \pm 12.4$ days The differences were statistically significant $(\mathrm{P}<0.001)$.

Complications after treatment. In the experimental group, we had no patient suffering from increased intraocular tension and no macular edema recurrence. We only observed 2 cases of visual acuity reduction in the experimental group. In the control group, we observed 2 cases of recurrence, 3 cases 
Table VI. Comparison of after treatment complications.

\begin{tabular}{lccccc}
\hline Groups & Case & $\begin{array}{c}\text { Recurrence of } \\
\text { macular edema }\end{array}$ & $\begin{array}{c}\text { Increase of } \\
\text { intraocular tension }\end{array}$ & $\begin{array}{c}\text { Deceases of } \\
\text { visual acuity }\end{array}$ & $\begin{array}{c}\text { Incidence of } \\
\text { complications }\end{array}$ \\
\hline Experimental & 39 & 0 & 0 & 2 & 0.05 \\
Control & 39 & 2 & 3 & 2 & 0.18 \\
P-value & - & 0.27 & 0.33 & \\
\hline
\end{tabular}

of increased intraocular tension and 2 cases of visual acuity reduction. The incidence of postoperative complications in the two groups were compared, and the differences were not statistically significant $(\mathrm{P}>0.05)$ (Table VI).

\section{Discussion}

Fundus macular edema is a condition that usually occur in medium stage of diabetes (1). Fundus macular edema has a complicated pathogeny and can be the ocular manifestation of multiple ocular diseases, including central retinal vein occlusion, diabetic retinopathy and uveitis. It is usually caused by diseases such as diabetes, retinal vein occlusion and uveitis. Fundus macular edema is considered an important cause of visual acuity reduction in elderly patients (2).

We know that an increase in VEGF level can promote the vitreous cell proliferation, optic nerve swelling and mottling bleeding, which finally lead to reduction of visual acuity (10). Therefore, if we find a way to decrease VEGF level in the vitreous chamber we can reduce the risk of fundus macular edema (11). In this study the recombinant humanized monoclonal antibody-Avastin ${ }^{\circledR}$ (Bevacizumab) was used to attach to VEGF in the vitreous chamber and block its biological activity. This method can be considered a targeted therapy $(2,9)$. In the past, Avastin ${ }^{\circledR}$ was also used in the targeted therapy and produced satisfactory results in treating mammary cancer, rectal cancer and liver cancer (12).

To treat fundus macular edema, we injected Avastin ${ }^{\circledR}$ into the vitreous chamber under local anesthesia, and demonstrated that Avastin ${ }^{\circledR}$ had an excellent effect in improving angiogenesis. However, its effect on the oxygen supplement on proliferated vessel and the choroid blood circulation was not ideal, and the visual acuity recovered slowly after treatment with Avastin ${ }^{\circledR}$.

Patients in our experimental group received Avastin ${ }^{\circledR}$ to stop neovascularization, and were treated with argon green laser to seal off the leaky microvascular artery. Thus we promoted the regeneration of the retina pigment epithelium and the rebuilding of the blood-retina barrier, and also accelerated the absorption of the edema. We treated the macular edema using two approaches and established good therapeutic effect. We achieved excellent results in improving patients' visual acuity. Results indicated that the macular foveal thickness in patients in the experimental group was obviously decreased after this treatment, and the decrease was more significant compared with that in the control group. Patients in the experimental group achieved the best-corrected visual acuity after one-month, while the patients in the control group achieve that after three months. When the postoperative adverse reactions (in the ocular region and whole body) were compared, no statistically significant differences were observed between the two groups.

Romero-Aroca et al treated macular edema caused by diabetes using laser and reported good outcome (1). However, the argon green laser cannot effectively reduce angiogenesis, therefore the probability of recurrences is fairly high.

Nevertheless, Avastin ${ }^{\circledR}$ therapy priority still needs further exploration with clinical and animal experiments. Also, financial aspect of these two methods for patients with limited financial resources should be studied in future. We concluded that treatment of fundus macular edema with Avastin ${ }^{\circledR}$ combined with argon green laser is safe and effective. This method obviously improved the visual acuity with relatively low adverse reactions.

\section{Acknowledgements}

The present study was supported by the National Natural Science Foundation of China (nos. 81160118, 81400372, 81300729 and 81470601), the Clinical Medicine Research Special-Purpose Foundation of China (no. L2012052), the ShanHai Foundation of China (no. 2013SH008), the Jiangxi Province Voyage Project (no. 2014022), the Science and Technology Platform Construction Project of Jiangxi Province (no. 2013116), the Natural Science Foundation of Fujian Province (no. 2015J05170), the Youth Science Foundation of Jiangxi (no. 20151BAB215016), the Technology and Science Foundation of Jiangxi Province (no. 20151BBG70223), the Education Department Scientific Research Foundation (no. GJJ14170) and the Health Development Planning Commission Science Foundation of Jiangxi Province (no. 20155154).

\section{References}

1. Romero-Aroca P, Reyes-Torres J, Baget-Bernaldiz M and Blasco-Suñe C: Laser treatment for diabetic macular edema in the 21st century. Curr Diabetes Rev 10: 100-112, 2014.

2. Shamsi HN, Masaud JS and Ghazi NG: Diabetic macular edema: new promising therapies. World J Diabetes 4: 324-338, 2013.

3. Chan CK, Jain A, Sadda S and Varshney N: Optical coherence tomographic and visual results at six months after transitioning to aflibercept for patients on prior ranibizumab or bevacizumab treatment for exudative age-related macular degeneration (an American Ophthalmological Society thesis). Trans Am Ophthalmol Soc 112: 160-198, 2014.

4. Luttrull JK and Dorin G: Subthreshold diode micropulse laser photocoagulation (SDM) as invisible retinal phototherapy for diabetic macular edema: a review. Curr Diabetes Rev 8: 274-284, 2012.

5. Sarraf D, Joseph A and Rahimy E: Retinal pigment epithelial tears in the era of intravitreal pharmacotherapy: risk factors, pathogenesis, prognosis and treatment (an American Ophthalmological Society thesis). Trans Am Ophthalmol Soc 112: 142-159, 2014. 
6. Bressler SB, Almukhtar T, Aiello LP, Bressler NM, Ferris FL 3rd, Glassman AR and Greven CM; Diabetic Retinopathy Clinical Research Network: Green or yellow laser treatment for diabetic macular edema: exploratory assessment within the Diabetic Retinopathy Clinical Research Network. Retina 33: 2080-2088, 2013.

7. Lee SJ, Kim ET and Moon YS: Intravitreal bevacizumab alone versus combined with macular photocoagulation in diabetic macular edema. Korean J Ophthalmol 25: 299-304, 2011.

8. Karim R, Sykakis E, Lightman S and Fraser-Bell S: Interventions for the treatment of uveitic macular edema: a systematic review and meta-analysis. Clin Ophthalmol 7: 1109-1144, 2013.

9. Stefanini FR, Badaró E, Falabella P, Koss M, Farah ME and Maia M: Anti-VEGF for the management of diabetic macular edema. J Immunol Res 2014: 632307, 2014.
10. Zhang Z, Wei Y, Jiang X, Qiu S and Zhang S: A machine-independent method to have active removal of 5,000 centistokes silicone oil using plastic infusion tube and 23-gauge microcannulas. BMC Ophthalmol 15: 114, 2015.

11. Oster SF,MojanaF, Bartsch DUG, Goldbaum MandFreeman WR: Dynamics of the macular hole-silicone oil tamponade interface with patient positioning as imaged by spectral domain-optical coherence tomography. Retina 30: 924-929, 2010.

12. Lordan JT, Wilkins M and Karanjia ND: Delayed bile leakwith avastin after liver resection for metastatic colorectalcancer. Hepatogastroenterology 58: 1769-1770, 2011. 